\title{
PREVENTION OF COAL RAW MATERIALS FREEZING BY MEANS OF ORGANOSILICON COMPOUNDS
}

PhD Shmeltser E. O., PhD Kormer M. V., ScD. Lyalyuk V.P.
State University of Economics and Technology, Kryvyi Rig, Ukraine

DOI: https://doi.org/10.31435/rsglobal_conf/30112020/7262

Abstract. This article authors represents the results of search for new reagents to prevent the freezing of coal in winter. Attention focuses on the physicochemical characteristics of silicone polymer, methods of introduction in coal concentrate and influence this reagent on freezing. The results of studies have shown that the use of organosilicon is more effective use of acetates and chlorides of metals. The high activity of organosilicon substances is explained by their elemental composition and structure of molecules.

Keywords: coal freezing, freezing point, degree of freezing, siloxane skeleton, silicone polymer.

Introduction. The freezing of coal in transit is a serious problem for the coal industry. From November or December on, the wet coal in railroad cars becomes a solid frozen mass. Turnaround times extend, rolling stock is held up at discharge sites, and rail customers complain of lost time. Preventive measures are required to prevent freezing of the coal to the walls of the railroad cars in cold weather.

The most promising preventive method is to reduce the pour point of the moisture's active component and reduce the strength of the bonds in the frozen coal. The materials employed should be harmless to the operating staff and the environment, should not cause corrosion of metal components, should not impair coal quality, should not significantly reduce the capacity of the rail car, should not require special storage conditions, and should mix well with coal.

The choice of a chemical to prevent the freezing of coal during its transportation in winter should be based on its efficiency and environmental friendliness, and should take into account the following aspects: the reagent must be dissolved in the outer moisture of the coal concentrate to form a solution, the concentration of which will ensure the flowability of the coal; preventative means should be inexpensive, affordable and environmentally friendly for service personnel, making their use economically and environmentally sound; must be resistant to changing weather conditions; not to adversely affect technological processes (coking, blast furnace melting) and product quality characteristics.

Results and discussions. In the present work, we continue the search for new reagents to prevent the freezing of coal in winter. The search for the most effective chemical preventive agent to prevent the freezing of coal concentrates in winter at very low temperatures during transportation from the supplier (coal processing plants) to coke plants showed that these requirements are satisfied when using silicone polymer.

Molecules of organosilicon compounds combine in part the structure of polymeric inorganic and organic molecules. The basis of their molecules is the siloxane skeleton - a chain of alternating atoms of silicon and oxygen. Other silicon bonds are compensated by organic radicals or groups of atoms [6].<smiles>[R][Si]([R])(C)O[Si]([R])([R])O[Si]([R])([R])OC</smiles>

where $\mathrm{R}-\mathrm{H}^{-}, \mathrm{CH}_{3}^{-}, \mathrm{C}_{6} \mathrm{H}_{5}^{-}$, and etc.

The peculiarity of the structure is associated with the unusual properties of these polymers, which combine the stability of these compounds to the action of low temperatures. Organosilicone liquid polymers can be obtained with a freezing temperature of minus $130^{\circ} \mathrm{C}$ or even lower.

A valuable property of silicone liquids is the weak dependence of their viscosity on temperature. Thus, as the temperature decreases, the viscosity of the organosilicon compounds increases to a lesser extent than for petroleum oils. This makes it easier to apply to the surface of a metal wagon and mix with coal [6].

For polysiloxanes, low freezing temperatures and chemical inertness to metals are typical. The flammability of organosilicon liquids is much lower than that of organic compounds. The final 
combustion products are carbon dioxide, water and silica as a fine powder. Polysiloxane fluids do not irritate the skin and eyes.

Thus, the most valuable technical properties of organosilicon liquids are determined by their physical and chemical properties: low pour point (minus 70 to minus $140{ }^{\circ} \mathrm{C}$ ), low viscosity dependence on temperature (multiplicity of viscosity change is 5-10 times in the interval temperature temps from -50 to $\left.+50^{\circ} \mathrm{C}\right)[6]$.

Emulsions of silicone polymers are stable structures of the type «oil in water». Due to the fact that it is practically more convenient to use aqueous emulsions of silicone liquids instead of their solutions in organic solvents, the industry produces $30-70 \%$ silicone emulsions. These emulsions are easily diluted with water and used in $5-10 \%$ concentration. In commercial form, the emulsions are a white mass of creamy consistency.

Molecules of organosilicon compounds contain an oxygen atom, so the electron density at oxygen atoms is localized. As a result, the reagents can specifically interact with the sorption-active centers of the coal surface bearing a positive charge (protonated hydrogen atoms of phenolic, carboxyl groups in macromolecules of organic mass of coal) according to the scheme:

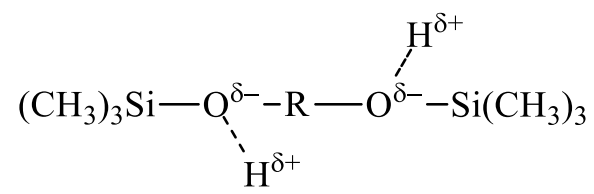

where $\mathrm{R}$-alkyl radical.

Molecules of oxygen-containing organosilicon compounds also contain hydrocarbon radicals that can interact with the apolar centers of the coal surface due to Van der Waals intermolecular forces. Therefore, when adsorbed on the coal surface, molecules of organosilicon exhibit both specific (hydrogen bonds) and universal nonspecific intermolecular forces of interaction with positive parts of the coal surface. This determines their high adsorption on the coal surface.

If the solution or emulsion is mixed with coal, these atoms or groups are reacted with the organic mass of the coal and water hydrate. Organosilicone bonds - Si - O - Si - O -, which provide physical and chemical interaction with the coal facing the surface, and organogenic groups framing the silicon atom in the opposite direction - outwards. The orientation of organosilicon bonds and hydrocarbon radicals when applied to the surface can be schematically represented Fig. 1.

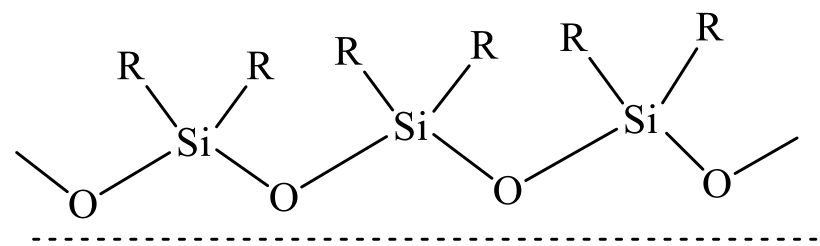

\section{Fig.1. Orientation of organosilicon bonds and hydrocarbon radicals on the coal surface}

Organosilicon compounds, when applied to a coal surface, react with water approximately molecule to molecule. The films of organosilicon compounds are very thin. The thickness of the film, which is calculated by the material flow and film weight, assuming that its density is equal to one, is $0.1 \cdot 10^{-6}-2.5 \cdot 10^{-5}$. The film on the surface is invisible, does not wear away when rubbed, does not wash off with water, is stable over a wide temperature range (from -200 to $+300{ }^{\circ} \mathrm{C}$ ). Polymeric silicones on the surface of coal, even in small quantities, provide a great water repellent effect.

For the experiment, a sample of coal weighing $500 \mathrm{~g}$ was taken, the moisture content of the coal was $12 \%$, the size class was $0-3 \mathrm{~mm}$. The coals were carefully treated with an emulsion. Next, the processed coal was loaded into a metal tank with a diameter of $50 \mathrm{~mm}$, height $50 \mathrm{~mm}$, without bottom and cover. This metal container was placed in the freezer and kept at a predetermined temperature for 24 hours. Then the tank was turned over, and the coal that was poured was weighed. The degree of freezing was thus determined. The study used an organosilicon fluid GKZh-94, which is a colorless slightly yellow liquid. Density - 0,996-1,003 g/ $\mathrm{cm}^{3}$; freezing temperature $-50{ }^{\circ} \mathrm{C} ; \mathrm{pH}$ not less than 6 . In water it is insoluble, but well forms an emulsion, corrosion inactive, does not emit harmful vapors and gases, weatherproof.

The organosilicon additive was used as 5 and $10 \%$ aqueous emulsions. The emulsion was thoroughly stirred with charcoal for 3-5 minutes. The amount of emulsion was changed from 4 to $40 \mathrm{~g}$ per $1 \mathrm{~kg}$ of coal. The concentration of the emulsion was 5 and $10 \%$. The results of the experiment are shown in Table 1. 
Table 1. The degree of freezing of the treated coal GCZh-94 emulsion at minus $15^{\circ} \mathrm{C}$

\begin{tabular}{|c|c|c|c|}
\hline $\begin{array}{c}\text { Quantity of } \\
\text { GCZh-94, g/kg }\end{array}$ & Mass of spilled coal, $\mathrm{g}$ & $\begin{array}{l}\text { Variation } \\
\text { of mass, } g\end{array}$ & $\begin{array}{c}\text { Degree of freezing, } \\
\%\end{array}$ \\
\hline \multicolumn{4}{|c|}{$5 \%$ emulsion } \\
\hline 4 & 150 & 350 & 70 \\
\hline 8 & 170 & 330 & 66 \\
\hline 12 & 190 & 310 & 62 \\
\hline 16 & 220 & 280 & 56 \\
\hline 20 & 260 & 240 & 48 \\
\hline 24 & 290 & 210 & 42 \\
\hline 28 & 310 & 190 & 38 \\
\hline 32 & 390 & 110 & 22 \\
\hline 36 & 450 & 50 & 10 \\
\hline 40 & 490 & 10 & 2 \\
\hline \multicolumn{4}{|c|}{$10 \%$ emulsion } \\
\hline 4 & 200 & 300 & 60 \\
\hline 8 & 220 & 280 & 56 \\
\hline 12 & 250 & 250 & 50 \\
\hline 16 & 270 & 230 & 46 \\
\hline 20 & 290 & 210 & 42 \\
\hline 24 & 360 & 140 & 28 \\
\hline 28 & 400 & 100 & 20 \\
\hline 32 & 420 & 80 & 16 \\
\hline 36 & 480 & 20 & 4 \\
\hline 40 & 500 & 0 & 0 \\
\hline
\end{tabular}

Studies have also been conducted to identify consumption rates of known and claimed prophylactic agents to prevent freezing of coal with a moisture content of $12 \%$ (Table 2).

The analysis of these tables shows that the organosilicon emulsions reduce the freezing point well, and when compared with salts it can be seen that the consumption of the organosilicon emulsion in comparison with the consumption of calcium chloride, magnesium and potassium acetate is lower.

Table 2. Dependence of the freezing point of the coal with a moisture content of $12 \%$ added of prophylactic agents

\begin{tabular}{|c|c|c|c|c|}
\hline \multirow{2}{*}{$\begin{array}{c}\text { Freezing point of } \\
\text { sample, }{ }^{\circ} \mathrm{C}\end{array}$} & \multicolumn{4}{|c|}{ Added of prophylactic agents, wt \% } \\
\cline { 2 - 5 } & $\mathrm{CaCl}_{2}$ & $\mathrm{MgCl}_{2}$ & $\mathrm{CH}_{3} \mathrm{COOK}$ & $\begin{array}{c}10 \% \\
\mathrm{GCZh}-94\end{array}$ \\
\hline-15 & 5,0 & 4,6 & 4,0 & 3,6 \\
\hline
\end{tabular}

Conclusions. Thus, the proposed method not only prevents the concentration of coal concentrates in winter during their transportation from the manufacturer to the coke plant, but also reduces the cost of coke by reducing the cost of defrosting (in greenhouses) and unloading coal, to prevent the corrosion of cars and equipment of coal-preparation shops of coke-chemical plants. Organosilicon compounds are less toxic. The use of organosilicon is more effective than the use of acetates and chlorides of metals. The high activity of organosilicon substances is explained by their elemental composition and structure of molecules.

\section{REFERENCES}

1. Ivanov, V.M. and Radovitskii, I.V., Predotvrashcheniepoter' i smerzaemosti uglei pri transportirovanii (Preventing loss and freezing of coal on transportation), Moscow: Nedra, 1979.

2. Kozhevnikov, N.N. and Popov, V.I., Prognozirovanie protsessov promerzaniya v spuchykh materialakh pri zheleznodorozhnykh perevozkakh (Predicting freezing in friable materials during rail transportation), Novosibirsk: Nauka, 1978.

3. Uchitel A.D. Transportation of Coal Concentrates at Negative Ambient Temperatures / Uchitel A.D., Kormer M.V., Lyalyuk V.P., Shmeltser E.O. et al // Coke and Chemistry. Vol. 56 (№5). 2013. pp.167-172

4. Kormer M.V. Dependens of coals freezing point on its granulometric composition / Kormer M.V., Lyalyuk V.P., Uchitel A.D., Shmeltser E.O., Lyakhova I.A. // Coke and Chemistry. Vol.58 (№1). 2015. pp. 9-14

5. Shmeltser E.O. Prevention of coal freezing by means of acetates / Shmeltser E.O., Kormer M.V., Lyalyuk V.P. et al // Coke and Chemistry.Vol.59 (№4). 2016. pp. 132-136

6. Sobalevskiy, M.V., Muzovskaya, O.A., Popeleva, G.S. Svoystva i primeneniye kremneorganicheskikh produktov (Properties and uses of organosilicon products), M.: Khimiya, 1975. 